\title{
Magnetometric evaluation of toxicities of chemicals to the lungs and cells
}

\author{
Yoshiharu Aizawa • Yuichiro Kudo
}

Received: 9 February 2009/Accepted: 6 December 2009/Published online: 6 April 2010

(C) The Japanese Society for Hygiene 2010

\begin{abstract}
Because the lungs are exposed to airborne hazardous materials, alveolar macrophages (AMs) play a major role in defending against the exposure to various noxious chemical substances. In this study, we reviewed magnetometric investigations of the effects of various chemicals on the lungs and AMs. Magnetometry, using magnetite as an indicator, was used to evaluate the effects of certain chemicals on the lung and AMs. A rapid decrease of the remanent magnetic field after the cessation of external magnetization, a phenomenon called relaxation, was impaired when the lungs and macrophages were exposed to toxic substances. The delayed in vivo relaxation observed in the lungs exposed to magnetite and gallium arsenide was almost identical to the in vitro relaxation observed in the AMs exposed to the same materials. Delayed relaxation was observed in the AMs exposed to silica dust; various fibers, such as chrysotile and some manmade mineral fibers; and toxic arsenic and cadmium compounds. The extracellular release of lactate dehydrogenase activity was found in the AMs exposed to the chemicals. Relaxation is attributed to the cytoskeletondriven rotation of phagosomes containing magnetite. While the exact mechanism of delayed relaxation due to exposure to harmful chemicals remains to be clarified, cell magnetometry appears to be useful for the safety screening of chemical substances.
\end{abstract}

Keywords Magnetometry · Toxicity · Lung · Macrophage $\cdot$ Chemicals

Y. Aizawa $\cdot$ Y. Kudo $(\square)$

Department of Preventive Medicine and Public Health, Kitasato University School of Medicine, 1-15-1 Kitasato, Sagamihara, Kanagawa 228-8555, Japan

e-mail: yuichiro@med.kitasato-u.ac.jp

\section{Introduction}

The lungs are target organs of several chemicals including particles, fibers, metals, and gases. Alveolar macrophages (AMs) are considered to play a major role in the protection of living things against various pathogens and chemical substances. These cells are phagocytic and initiate the pathogenic process leading to inflammation and fibrotic lung diseases. Therefore, AMs have been used for the in vitro evaluation of the toxic effects of chemicals. Using the rate of relaxation as an indicator of the cytoskeletal function of cells by magnetometry, we have found several chemicals affecting relaxation [1-5]. The magnetometric measurement of lung contamination of magnetite was developed by Cohen [6]. His coworker, Kotani, introduced lung magnetometry to Japan in 1977. Chiyotani reported the estimation of dust burden in the lungs of foundry workers using the magnetometric apparatus developed by Kotani [7]. Aizawa and colleagues [8] applied lung magnetometry in rabbits to evaluate the toxicity of gallium arsenide (GaAs) and later developed cell magnetometry using the AMs of hamsters and rats for the evaluation of various chemical substances, including GaAs. More than ten chemical substances have been evaluated for their toxicity by magnetometry.

\section{Lung magnetometry in humans}

The principle of magnetometry is to administer iron oxide particles to lungs and to allow AMs to engulf them. By the application of external magnetization, the iron oxide particles located in the phagosomes of macrophages are magnetized and aligned in a magnetic field. The remanent magnetic field (RMF) decreases rapidly upon the cessation 
of external magnetization as time passes, a phenomenon called relaxation. Relaxation occurs due to the cytoskeleton-driven random rotation of phagosomes that contain magnetized iron oxide particles [9]. Therefore, delayed relaxation indicates dysfunction of the cytoskeleton. As shown in Fig. 1, a 5-min period of relaxation was fitted to the exponential function, $B=B_{0} e(-\lambda t)$, where $B$ is the $\mathrm{RMF}$ at time $t ; B_{0}$ the RMF at time $=0$; $e$ is the exponent; $t$ is the time (in seconds) from the termination of magnetization; and $\lambda$ is the relaxation rate (decay constant) for 5 min [10].

Because the RMF immediately after the cessation of external magnetization indicates the amount of magnetized dust in the lung, lung magnetometry is used to evaluate the burden of inhaled dust among workers such as welders and foundry workers [11, 12]. Cohen et al. [13] observed a significant relation between asbestos retention in the lungs and the exposure index in asbestos miners and combustion workers. The compensated ex-miners were found to present with more intensive RMF than were miners and healthy nonexposed persons [14].

Chiyotani disclosed that the lungs of foundry workers with roentgenological categories exceeding $1 / 1$ contained $100 \mathrm{mg}$ or more of magnetizable dust, even though clear dose-dependent findings were not shown [7]. Magnetometry was applied for the evaluation of the lung burden of magnetizable dust in welders to find the association of dust burden of magnetites with pulmonary function tests [15]. Because pneumoconiosis is a chronic irreversible and progressive disease, measurement of the burden of dust in the lungs is more useful than is early detection of pneumoconiosis by chest roentgenogram. However, the application of lung magnetometry for exposure evaluation is limited to magnetizable dust.

The repetition of magnetization and measurements of RMF demonstrate the clearance of iron oxide particles
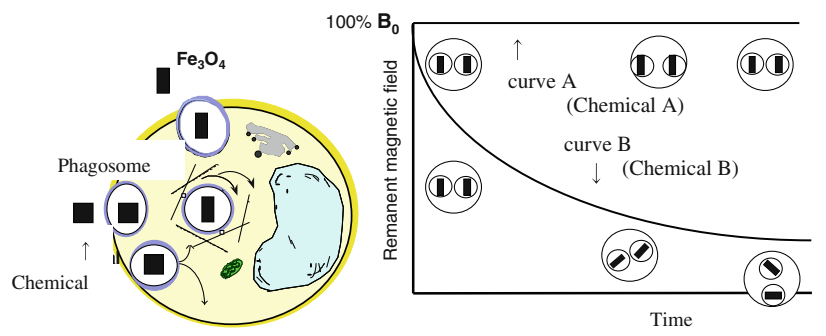

Fig. 1 Relaxation curve of RMF and the suggested behavior of magnetic particles after magnetization. A 5-min period of relaxation was fitted to the exponential function, $B=B_{0} e(-\lambda t)$, where $B$ is the $\mathrm{RMF}$ at time $t ; B_{0}$ the RMF at time $=0 ; e$ is the exponent; $t$ is the time (in seconds) from the termination of magnetization; and $\lambda$ is the relaxation rate (decay constant) for $5 \mathrm{~min}$. Relaxation curve $A$ represents impaired cytoskeletal movement, and curve $B$ represents normal cytoskeletal movement with rapid decrease of RMF from the lungs. Smokers showed delayed clearance of inhaled iron oxide particles from the lungs compared with nonsmokers [16]. Spherical ferromagnetic iron oxide particles were inhaled by patients with primary ciliary dyskinesia, and their airway clearance was retarded compared to that of healthy nonsmokers [17].

\section{Lung magnetometry in animals}

Aizawa et al. [1] applied lung magnetometry to rabbits to evaluate the lung toxicity of GaAs, as shown in Fig. 2 . After instillation of GaAs and iron oxide particles into the trachea, a $50 \mathrm{mT}$ magnetic field was applied to the thorax of an anesthetized rabbit placed on a board between a pair of enameled copper wire coils driven by a DC power supply. Each animal was exposed to this field for $15 \mathrm{~s}$ for magnetization. After removal of the external magnetic field, the RMF in the chest was measured by a fluxgate magnetometer for at least $40 \mathrm{~min}$. The relaxation and clearance of iron oxide particles in the rabbits concurrently exposed to GaAs were dose-dependently impaired. Histological findings of GaAs-exposed rabbits showed marked cellular infiltration in the alveolar space and interstitial space [8]. Because definite delay of relaxation and clearance was not observed in the rabbits exposed to $\mathrm{Ga}_{2} \mathrm{O}_{3}$, As in the lungs appears to be responsible for the lung damage.

\section{Mechanism of relaxation}

The mechanism of relaxation observed in lung magnetometry has been clarified by the magnetometry of cultured cells. Morphological and pharmacological studies have indicated the relaxation occurred due to the energydependent random rotation of phagosomes containing magnetite $[9,18,19]$. The rotation of phagosomes

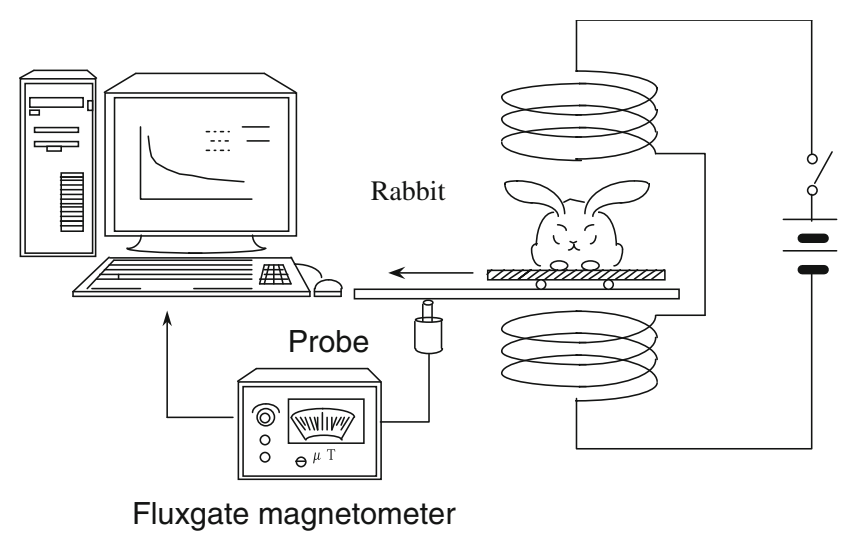

Fig. 2 Apparatus of lung magnetometry for rabbits 
containing magnetizable particles has been examined by high-performance videoanalysis, magnetometry, and immunofluorescence analysis when the cells were exposed to the cytoskeleton disturbing chemical, vinblastine. A high-resolution videoscopic examination with 10,000 magnitude showed the iron particles to be aligned in the external field and misaligned immediately after cessation of magnetization. When the cells were exposed to vinblastine $5 \times 10^{-4} \mathrm{M}$, the movement of the aggregated iron particles appeared disturbed. Immunofluorescent staining using anti- $\alpha$ microtubulin antibody did not show a meshlike microtubular network structure in the cells exposed to $5 \times 10^{-3} \mathrm{M}$ vinblastine, though the structure was observed in the unexposed cells. The magnetometric analysis showed delayed relaxation in the cells exposed to $5 \times 10^{-3} \mathrm{M}$ vinblastine but demonstrated almost normal relaxation in the cells exposed to $5 \times 10^{-4} \mathrm{M}$ or lower vinblastine. Therefore, the videoscopic movement of clustered iron particles in the field and a mesh-like structure in immunofluorescent staining appeared to be related to the speed of relaxation by magnetometry, despite the difference in effective vinblastine doses.

\section{Toxicity evaluation using cell magnetometry and other supportive examinations}

We applied cell magnetometry for the screening of toxicity of various chemical substances [2]. The samples of chemical substances were suspended in phosphate-buffered saline and mixed by ultrasonic oscillation before use. Iron oxide particles with a mean geometric diameter of $0.26 \mu \mathrm{m}$ were used as the magnetometric index. Male hamsters $[2,3]$ or F344/NS1c rats [20] were anesthetized and bronchoalveolar lavage fluid was obtained. The harvested cells, about six million cells, were divided into two groups: one group was exposed to different doses of chemicals, and the other group was exposed to phosphate-buffered saline as a control. Both groups included $\mathrm{Fe}_{3} \mathrm{O}_{4}$ as an indicator of magnetometry. Recently, the RAW264.7 cell line was used instead of harvested AMs, showing no remarkable difference from previous cells [21].

Cell disks (sample) were removed from the wells after $18 \mathrm{~h}$ in a $5 \%-\mathrm{CO}_{2}$ incubator. Glass tubes containing medium and a cell disk on the bottom were installed on a stage and magnetized in $70 \mathrm{mT}$ for $10 \mathrm{~ms}$. Then the stage was turned at $10 \mathrm{rpm}$ above the probe of a fluxgate magnetometer surrounded by a shield to protect it from noise from outside and maintained at $37^{\circ} \mathrm{C}$ with a heater [2] (Fig. 3). Relaxation, a rapid decrease of the RMF strength radiated from phagocytized iron oxide particles in macrophages after the cessation of external magnetization, was used as an indicator of cellular function (Fig. 3).

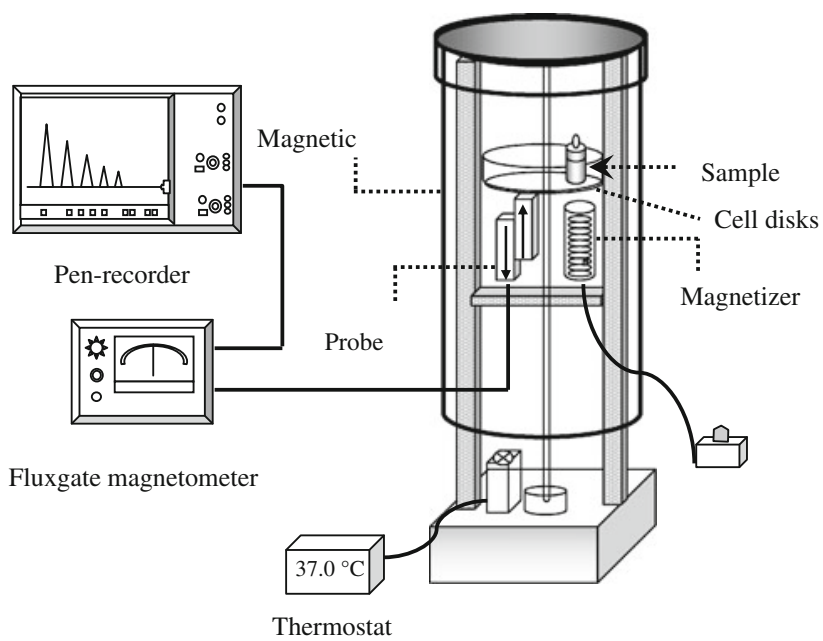

Fig. 3 Apparatus of cell magnetometry

We evaluated the release of intracellular enzyme lactate dehydrogenase (LDH) activity with an LDH-UV test. Triton-X 100 was added to the control group to measure the total LDH activation index derived from both the intracellular and the extracellular matrices. The LDH release rate (\%) was calculated using the following equation: (LDH activation index from exposed-cells) $\times 100 /$ (total LDH activation index). Macrophages that adhered to glass were used for observation by scanning electron microscopy and transmission electron microscopy. Apoptosis was evaluated by both the terminal deoxynucleotidyl transferase-mediated dUTP-biotin nick end labeling (TUNEL) method and the DNA ladder method [3]. The DNA ladder method was performed in two steps, DNA extraction and agarose gel electrophoresis.

We evaluated the cytotoxic effects of the following chemicals, particles, and fibrous materials as compounds [3, 22, 23], cadmium (Cd) compounds [24, 25], silica [26] or other dust, chryosotile fibers (CFs) [2], and five manmade mineral fibers (MMMFs) [4, 5], using the abovementioned tests, and the results are shown in Table 1. On the basis of magnetometry and the LDH release assay, we estimated that there were no observable adverse effect levels (NOAEL) on the cells.

Arsenic and compounds used in the microelectronics industry

GaAs has been used as a material in various microelectronics products, but was reported to cause toxic effects to the lungs of animals. An in vitro magnetometric study revealed that relaxation was delayed dose-dependently due to exposure to GaAs. LDH release was increased in GaAsexposed cells. According to DNA electrophoresis and the 
Table 1 Cytotoxicity evaluation by cell magnetometry

\begin{tabular}{|c|c|c|c|c|}
\hline & Delayed relaxation (estimated NOAEL) & Extracellular LDH\% (estimated NOAEL) & Ultra-structure & Apoptosis \\
\hline \multicolumn{5}{|l|}{ Particulates } \\
\hline Silica & Moderate $(<20 \mu \mathrm{g} / \mathrm{ml})$ & Moderate $(<20 \mu \mathrm{g} / \mathrm{ml})$ & Necrosis & ND \\
\hline $\mathrm{Ca}_{2} \mathrm{CO}_{3}$ & Negligible $(60 \mu \mathrm{g} / \mathrm{ml})$ & Negligible $(60 \mu \mathrm{g} / \mathrm{ml})$ & Negligible & ND \\
\hline $\mathrm{GaAs}$ & Marked $(2 \mu \mathrm{g} / \mathrm{ml})$ & Marked $(<2 \mu \mathrm{g} / \mathrm{ml})$ & Necrosis & Negative \\
\hline InAs & Negligible $(20 \mu \mathrm{g} / \mathrm{ml})$ & Negligible $(20 \mu \mathrm{g} / \mathrm{ml})$ & Negligible & Negative \\
\hline $\mathrm{CdO}$ & Marked $(0.1 \mu \mathrm{g} / \mathrm{ml})$ & Marked $(1 \mu \mathrm{g} / \mathrm{ml})$ & Necrosis & Negative \\
\hline $\mathrm{pTiO}_{2}$ & Negligible $(60 \mu \mathrm{g} / \mathrm{ml})$ & Negligible $(60 \mu \mathrm{g} / \mathrm{ml})$ & Negligible & Negative \\
\hline Toner & Negligible $(60 \mu \mathrm{g} / \mathrm{ml})$ & Negligible $(60 \mu \mathrm{g} / \mathrm{ml})$ & Negligible & Negative \\
\hline \multicolumn{5}{|l|}{ Fibers } \\
\hline Chrysotile & Moderate $(15 \mu \mathrm{g} / \mathrm{ml})$ & Moderate $(15 \mu \mathrm{g} / \mathrm{ml})$ & Negligible & Negative \\
\hline $\mathrm{SiC}$ & Moderate $(<20 \mu \mathrm{g} / \mathrm{ml})$ & Negligible $(60 \mu \mathrm{g} / \mathrm{ml})$ & Nucleus & Suspected \\
\hline $\mathrm{fTiO}_{2}$ & Mild $(40 \mu \mathrm{g} / \mathrm{ml})$ & Moderate $(20 \mu \mathrm{g} / \mathrm{ml})$ & Negligible & Negative \\
\hline PT & Moderate $(10 \mu \mathrm{g} / \mathrm{ml})$ & Moderate $(10 \mu \mathrm{g} / \mathrm{ml})$ & Negligible & Negative \\
\hline Microglass & Negligible $(160 \mu \mathrm{g} / \mathrm{ml})$ & Mild $(80 \mu \mathrm{g} / \mathrm{ml})$ & Negligible & ND \\
\hline Rock wool & Negligible $(150 \mu \mathrm{g} / \mathrm{ml})$ & Negligible $(150 \mu \mathrm{g} / \mathrm{ml})$ & Negligible & Negative \\
\hline \multicolumn{5}{|l|}{ Solution } \\
\hline $\mathrm{CdCl}_{2}$ & Marked $(<1 \mu \mathrm{g} / \mathrm{ml})$ & Marked $(<1 \mu \mathrm{g} / \mathrm{ml})$ & ND & Suspected \\
\hline $\mathrm{AsCl}_{3}$ & Marked $(<2 \mu \mathrm{g} / \mathrm{ml})$ & Marked $(<2 \mu \mathrm{g} / \mathrm{ml})$ & ND & ND \\
\hline
\end{tabular}

Estimated NOAEL represents the level with no significantly affected relaxation or release of LDH in the exposed cells compared with controls $N D$ not done, NOAEL no observable adverse effect level, $L D H$ lactate dehydrogenase, GaAs gallium arsenide, InAs indium arsenate, $C d O$ cadmium oxide, $\mathrm{pTiO}_{2}$ particle titanium dioxide, $\mathrm{SiC}$ silicon carbide, $f \mathrm{TiO}_{2}$ fibrous titanium dioxide, $\mathrm{PT}$ potassium octatitanate whisker

TUNEL method, apoptotic changes failed to be detected [3]. Because $\mathrm{AsCl}_{3}$ alone caused effects identical to those of GaAs on magnetometry and LDH release in macrophages, and $\mathrm{Ga}_{2} \mathrm{O}_{3}$ did not show significant effects, it was concluded that As was responsible for the toxicity to macrophages [22]. Indium arsenate and indium phosphate, which are also used for light-emission semiconductors, showed neither delayed relaxation nor increased LDH release [23].

\section{Cadmium}

Cd is an industrial and environmental pollutant, found primarily in batteries, electroplating, pigment, plastic, fertilizer, and cigarette smoke. Although the kidney is a major target of Cd-induced toxicity, the respiratory system is also affected, where $\mathrm{Cd}$ produces bronchitis, pulmonary edema, pneumonitis, and emphysema [24]. Two Cd compounds, the insoluble material $\mathrm{CdO}$ and a soluble form, $\mathrm{CdCl}_{2}$, delayed relaxation markedly and increased the $\mathrm{LDH}$ release from exposed macrophages [25, 26].

Particulate materials

Exposure to silica $\left(\mathrm{SiO}_{2}\right)$ is known to develop silicosis in humans, and the cytotoxicity of $\mathrm{SiO}_{2}$ to phagocytes is well known. Relaxation was moderately delayed and significant extracellular release of LDH was observed when AMs were exposed to $\mathrm{SiO}_{2}$ [27].

$\mathrm{CaCO}_{3}$ is used for cement production and for environmental protection. Neither cell magnetometry nor LDH release assays indicate cell damage to macrophages due to $\mathrm{CaCO}_{3}$ exposure [27].

Photocopier toner has been suspected to develop pneumonitis in workers possibly exposed to toner [28, 29]. However, neither cell magnetometry nor the LDH release assay suggested adverse effects of toner on AMs [30]. Neither did particulate titanium dioxide $\left(\mathrm{TiO}_{2}\right)$ exposure affect relaxation or LDH release; however, fibrous $\mathrm{TiO}_{2}$ significantly delayed relaxation and increased LDH release [31].

\section{Chrysotile and MMMFs}

CFs [2], silicon carbide whiskers [4], $\mathrm{TiO}_{2}$, and potassium octatitanate whiskers $[20,31]$ appeared to have similar toxicity. Microglass demonstrated milder toxicity than did the other four fibers. Rock wool (RW) [32]-exposed cells did not show toxicity in the range of the applied doses. Apoptosis was suspected in AMs only when exposed to silicon carbide, determined by DNA ladder detection, TUNEL, and electron microscopy showing condensed 
chromatin in the nuclei. The nontoxic nature of RW was confirmed by earlier clearance in rats after inhalation of RW than chrysotile [33].

\section{Conclusions}

Magnetometric studies show that RMFs generated from iron oxide particles in AMs following external magnetization decrease rapidly. Lung magnetometry demonstrates relaxation and clearance of magnetite from the lungs. Cell magnetometry also demonstrates relaxation, the speed of decrease of RMF, indicating cytoskeletal function. The delay of relaxation generally corresponded with the release of the cytoplasmic enzyme LDH due to cell membrane damage. A combination of the no-observable-adverseeffect level of magnetometric behavior with that of $\mathrm{LDH}$ release from cells exposed to various substances indicates the toxicity of chemicals. Therefore, this method could be used for the safety screening of new industrial materials. Further exposure studies using animals, and epidemiological studies, are warranted for any suspected toxic chemical substances.

Acknowledgments This study was supported in part by Grant in Aid for Scientific Research B of the Ministry of Education, Culture, Sports, Science and Technology, Japan.

\section{References}

1. Aizawa Y, Takata T, Karube H, Tatsumi H, Inokuchi N, Kotani $\mathrm{M}$, et al. Magnetometric evaluation of the effects of gallium arsenide on the clearance and relaxation of iron particles. Ind Health. 1993;31:143-53.

2. Keira T, Okada M, Katagiri H, Aizawa Y, Okayasu I, Kotani M. Magnetometric evaluation for the effect of chrysotile on alveolar macrophages. Tohoku J Exp Med. 1998;186:87-98.

3. Okada M, Karube H, Niitsuya M, Aizawa Y, Okayasu I, Kotani M. In vitro toxicity of gallium arsenide in alveolar macrophages evaluated by magnetometry, cytochemistry and morphology. Tohoku J Exp Med. 1999;189:267-81.

4. Watanabe M, Okada M, Aizawa Y, Sakai Y, Yamashina S, Kotani M. Magnetic evaluation for the effects of silicon carbide whiskers on alveolar macrophages. Ind Health. 2000;38:239-45.

5. Shinji H, Watanabe M, Kudo Y, Niitsuya M, Tsunoda M, Satoh $\mathrm{T}$, et al. The cytotoxicity of microglass fibers on alveolar macrophages of Fischer 344 rats evaluated by cell magnetometry, cytochemistry and morphology. Environ Health Prev Med. 2005; 10:111-9.

6. Cohen D. Ferromagnetic contamination in the lungs and other organs of the human body. Science. 1973;180:745-8.

8. Aizawa Y, Takata T, Karube H, Nakamura K, Kotani M. Effects of $\mathrm{GaAs}$ and $\mathrm{Ga}_{2} \mathrm{O}_{3}$ on magnetometric behavior of iron oxide particles in rabbit lungs. Appl Organomet Chem. 1994;8:207-13.

9. Nemoto I, Ogura K, Toyotama H. Estimation of the energy of cytoplasmic movements by magnetometry: effects of temperature and intracellular concentration of ATP. IEEE Trans Biomed Eng. 1989;36:598-607.
10. Brain JD, Bloom SB, Hu T, Gehr P, Valberg PA. Magnetic iron dust as a probe of particle clearance, phagocytosis, and particle cytotoxicity in the lungs. Ann Occup Hyg. 1988;32(Suppl 1):783-93.

11. Freedman AP, Robinson SE, Green FH. Magnetopneumography as a tool for the study of dust retention in the lung. Ann Occup Hyg. 1982;26:319-35.

12. Kalliomaki PL, Tuomisaari M, Lakomaa EL, Kalliomaki K, Kivela R. Retention and clearance of stainless steel shieldgas welding fumes in rat lungs. Am Ind Hyg Assoc J. 1983;44:64954.

13. Cohen D, Crowther TS, Gibbs GW, Becklake MR. Magnetic lung measurements in relation to occupational exposure in asbestos miners and millers of Quebec. Environ Res. 1981;26:535-50.

14. Freedman AP, Robinson SE, Johnston RJ. Non-invasive magnetopneumographic estimation of lung dust loads and distribution in bituminous coal workers. J Occup Med. 1980;22:613-8.

15. Nakadate T, Aizawa Y, Yagami T, Zheg YQ, Kotani M, Ishiwata $\mathrm{K}$. Change in obstructive pulmonary function as a result of cumulative exposure to welding fumes as determined by magnetopneumography in Japanese arc welders. Occup Environ Med. 1998;55:673-7.

16. Cohen D, Arai SF, Brain JD. Smoking impairs long-term dust clearance from the lung. Science. 1979;204:514-7.

17. Moller W, Haussinger K, Ziegler-Heitbrock L, Heyder J. Mucociliary and long-term particle clearance in airways of patients with immotile cilia. Respir Res. 2006;19:7-10.

18. Gehr P, Brain JD, Nemoto I, Bloom SB. Behavior of magnetic particles in hamster lungs: estimates of clearance and cytoplasmic motility. J Appl Physiol. 1983;55:1196-202.

19. Valberg PA, Butler JP. Magnetic particle motions within living cells: physical theory and techniques. Biophys J. 1987;52:53750 .

20. Watanabe M, Shibata K, Okada M, Kudo Y, Niitsuya M, Satoh T, et al. Magnetometric evaluation for cytotoxicity of potassium octatitanate whisker on alveolar macrophages of Fischer 344 rats. J Occup Health. 2002;44:321-8.

21. Shibata K, Kudo Y, Tsunoda M, Hosokawa M, Sakai Y, Kotani $\mathrm{M}$, et al. Magnetometric evaluation of the effects of man-made mineral fibers on the function of macrophages using the macrophage cell line RAW 264.7. Ind Health. 2007;45:426-36.

22. Okada M, Inoue Y, Karube H, Niitsuya M, Tohnori H, Aizawa Y, et al. Cytotoxic evaluation of arsenic compounds in alveolar macrophages in hamsters. Appl Organomet Chem. 2001;15:25260.

23. Okada M, Watanabe M, Lyons YI, Sugiura Y, Kudo Y, Shinji H, et al. In vitro toxicity of indium arsenide to alveolar macrophages evaluated by magnetometry, cytochemistry and morphological analysis. Toxicol Lett. 2002;134:185-94.

24. Newman-Taylor AJ. Cadmium. In: Rom WN, editor. Environmental occupational medicine. 3rd ed. New York: LippincottRaven; 1998. p. 1005-10.

25. Niitsuya M, Watanabe M, Okada M, Shinji H, Satoh T, Aizawa $\mathrm{Y}$, et al. Magnetometric evaluation of cadmium oxide-induced toxicity to pulmonary alveolar macrophages of Syrian golden hamsters. J Toxicol Environ Health A. 2003;66:365-78.

26. Chou YC. In vitro magnetometry, LDH activity and apoptosis as indices of cytotoxicity in alveolar macrophages exposed to cadmium chloride. Korean J Environ Health Soc. 2000;26:115-21.

27. Keira T, Karube H, Aizawa Y, Niitsuya M, Shinohara S, Kuwashima A, et al. Effect of limestone on the alveolar macrophages of hamsters. Jpn J Traumatol Occup Med. 1996;44:313-8. (article in Japanese).

28. Gallardo M, Romero P, Sanchez-Quevedo MC, Lopez-Caballero JJ. Siderosilicosis due to photocopier toner dust. Lancet. 1994;344:412-3. 
29. Armbruster C, Dekan G, Hovorka A. Granulomatous pneumonitis and mediastinal lymphadenopathy due to photocopier toner dust. Lancet. 1996;348:1518-9.

30. Furukawa Y, Aizawa Y, Okada M, Watanabe M, Niitsuya M, Kotani M. Negative effect of photocopier toner on alveolar macrophages determined by in vitro magnetometric evaluation. Ind Health. 2002;40:214-21.

31. Watanabe M, Okada M, Kudo Y, Tonori Y, Niitsuya M, Sato T, et al. Difference in the effects of fibrous and particulate titanium dioxide on alveolar macrophages of Fischer 344 rats. J Toxicol Environ Health A. 2002;65:1047-60.

32. Kudo Y, Watanabe M, Okada M, Shinji H, Niitsuya M, Satoh T, et al. Comparative cytotoxicity study of rock wool and chrysotile by cell magnetometric evaluation. Inhal Toxicol. 2003;15:1275-95.

33. Kudo Y, Shibata K, Miki T, Ishibashi M, Hosoi K, Sato T, et al. Behavior of new type of rock wool (HT Wool) in lungs after exposure by nasal inhalation in rats. Environ Health Prev Med. 2005;10:239-48. 